\title{
EDUCAÇÃO AMBIENTAL E SEUS DESÁFIOS NO ENSINO SUPERIOR: Um Estudo de caso do Instituto Federal de Educação, Ciência e Tecnologia do Pará, Campus Bragança
}

\author{
Igor Padilha de Souza ${ }^{1}$ \\ Laila Suellen Santana Chaves ${ }^{2}$ \\ Lena Claudia dos Santos Amorim Saraiva ${ }^{3}$ \\ Marcos Ronielly da Silva Santos ${ }^{4}$ \\ Marcelo Santos de Mendonça ${ }^{5}$
}

\section{RESUMO}

A Educação Ambiental na perspectiva de uma sociedade consciente quanto ao desenvolvimento de forma sustentável no planeta tem sido objeto de vários debates nacionais e internacionais, que produziram uma série de recomendações e orientações para sua implementação como prática sistemática nas escolas. Neste contexto esse artigo analisa a educação ambiental e seus desafios no ensino superior; levando em consideração uma Instituição Federal de Educação Pública. A metodologia da pesquisa está pautada na aplicação de questionários e revisão bibliográfica sobre os temas: educação ambiental, práticas de ensino e ensino superior. $O$ artigo foi organizado em três etapas fundamentais: levantamento bibliográfico, coleta de dados e sistematização dos resultados. A partir dos procedimentos metodológicos empregados na pesquisa considera-se que a educação ambiental é tratada de forma rasa e transversal nos currículos e práticas no ensino superior. Ausentando-se de muitos processos formativos e educacionais pela necessidade de professores de áreas afins e pelo baixo número livros e ações metodológicas que tratem e divulguem o tema proposto.

Palavras-chave: Educação ambiental; Ensino superior; Instituição de ensino.

\footnotetext{
${ }^{1}$ Especialista em Docência no Ensino Superior pela Faculdade Pan Americana(2015), Graduado do Curso de Tecnologia em Gestão Ambiental do Instituto Federal de Educação, Ciência e Tecnologia do Pará (2014). E-mail: igorsouza 21@yahoo.com.br

${ }^{2}$ Professora efetiva da SEDUC-MA.E-mail: laila.suellen@hotmail.com

${ }^{3}$ Mestre em Antropologia pela Universidade Federal do Pará. Docente da Faculdade Pan Americana.E-mail: I-claudia-amorim@bol.com.br

4 Doutorando do Programa de Pós-Graduação em Ciências Ambientais UFPA/EMBRAPA/MPEG.E-mail: mronielly@yahoo.com.br

${ }^{5}$ Especialista em Docência do Ensino Superior, na Faculdade PAN AMERICANA.E-mail: marcelo mendonca03@hotmail.com
} 


\title{
ENVIRONMENTAL EDUCATION AND ITS DISASTERS IN HIGHER EDUCATION: A case study of the Federal Institute of Education, Science and Technology of Pará, Campus Bragança
}

\begin{abstract}
Environmental Education in the perspective of a sustainable society on sustainable development on the planet has been the subject of several national and international discussions, which produced a series of recommendations and guidelines for its implementation as a systematic practice in schools. In this context this paper analyzes the environmental education and its challenges in higher education; taking into account a Federal Public Education Institution. The research methodology that guided the deductive-inductive method, with the use of questionnaires and literature review on the themes: environmental education, teaching practices and higher education. The article is organized in three basic steps: literature review, data collection and systematization of the results. From the methodological procedures used in the research is considered that environmental education is treated in shallow cross in the curricula and practices in higher education. Absent from many training and educational processes by the need of related areas of teachers and the low number methodological books and actions that address and publicize the proposed theme.
\end{abstract}

Keywords: Environmental Education; Higher education; Educational institution.

\section{INTRODUÇÃO}

A atual conjuntura ambiental está interligada a nossa percepção de educação ambiental, Segundo Carvalho (2006) a Educação Ambiental é concebida inicialmente como preocupação dos movimentos ecológicos com a prática de conscientização capaz de chamar a atenção para a finitude e má distribuição do acesso aos recursos naturais e envolver os cidadãos em ações sociais ambientalmente apropriadas.

Outrora se visualizava a educação ambiental somente com a aplicação de ações simplórias como: não jogar resíduos em rios e vias, plantar árvores não desperdiçar água e etc. Todavia frente aos decorrentes acidentes ambientais, percebesse que tais ações não respondem a complexidade dos impasses ambientais. Verifica-se que construindo conhecimento em "Educação Ambiental é onde se tem uma percepção coerente do que se passa no nosso 
planeta, a informação é um instrumento modificador da consciência do homem e de seu grupo". (BARRETO, 1994).

Portanto, a educação ambiental como prevista na Constituição Federal deve ser inserida em todos os níveis de ensino, para que futuramente possam se ter pessoas conscientes da importância de um meio ambiente ecologicamente equilibrado. Devido essa grande preocupação com o meio ambiente é que se acredita que a educação ambiental é a única estratégia para uma mudança efetiva. Entende-se que educação ambiental pode ser aplicada de diversas formas, mas com uma única finalidade, construir "valores sociais, conhecimentos, habilidades, atitudes e competências voltadas para a conservação do meio ambiente". (BRASIL, 1981)

Nesse ínterim a Educação Ambiental faz-se de suma importância para aplicação no nível superior, no intuito de formar pesquisadores e discentes de qualidade para tentar minimizar os problemas ambientais. Diante do exposto esta pesquisa objetiva, caracterizar e descrever a necessidade de uma formação de qualidade específica para se trabalhar a educação ambiental no ensino superior, contextualizando os desafios e o olhar do docente e discente que compõem o quadro formativo do Instituto Federal de Ciências e Tecnologia do Pará, campus Bragança.

Mediante aos problemas ambientais é necessário à formação de qualidade de discente no ensino superior, que enveredem pela educação ambiental. A questão ambiental é uma área bastante recente dentro do campo educacional, seus primeiros discursos decorrem da década de setenta (MININNI, 1994), sendo assim, a educação ambiental ainda encontra-se em estruturação epistemológica. Neste sentido é viável que se ofereça cursos superiores com bons professores qualificados, equipamentos adequados e suporte técnico-informacional capaz de absorver e buscar soluções para atual questão ambiental.

A problemática encontrada nas instituições de ensino sobre a questão ambiental pode estar ligada aos desafios técnico-formativos dos docentes e das Instituições de Ensino superior (IES). Atrelado a isto, visualiza-se a falta de conscientização sobre o assunto por parte do discente, que se intensifica na falta de profissionais específicos, a falta de projetos ambientais e a não e/ou pouca utilização do espaço interno do instituto para trabalhos de aula. 
As hipóteses para os reais desafios da educação ambiental do ensino superior perpassam pela tímida oferta de cursos superiores disponibilizados pelas instituições de ensino superior, apesar da grande discussão ambiental ainda é ínfima a oferta de curso que formem para somar a problemática ambiental. E outra possível hipótese é a pouca formação dos docentes em áreas específicas sobre meio ambiente.

A base teórica desta pesquisa fundamentou-se em três autores principais que nortearam e embasaram o tema proposto sendo eles Carvalho (2006) que discuti o conceito da educação ambiental; Philippi Jr. (2005) que apresenta os desafios do ensino-aprendizagem da educação ambiental no ensino em instituições e Meirelles (2005) que proporciona o debate e o discurso acerca da introdução da questão ambiental nos currículos superiores a partir do pensamento reflexivo.

A presente análise objetiva de forma geral verificar os desafios da questão ambiental dentro do ensino superior, levando em particularidade a instituição de ensino pública federal. Para isto tem como objetivos específicos: Entender a necessidade da educação ambiental nos currículos de ensino superior; Verificar os desafios epistemológicos e formativos dos docentes; Verificar a percepção elou conceito dos docentes tendo como foco a educação ambiental.

Neste contexto o presente artigo busca analisar as condições e desafios enfrentados pelos docentes do ensino superior na aplicação de metodologias e práticas na educação ambiental, bem como nas disciplinas e cursos específicos na preparação de profissionais da área.

A área de estudo selecionada foi a Instituição de Ensino Superior (IES) do Instituto Federal de Educação, Ciência e Tecnologia do Pará (IFPA), campus Bragança. O mesmo foi objeto do estudo por apresentar-se como uma excelente instituição de ensino para toda a região Bragantina e apresentar um grande quadro de docentes e oferecer diversos cursos na área da educação, principalmente os correlacionados ao meio ambiente (Tecnologia em Gestão ambiental e agroecologia).

O IFPA também apresenta uma boa infraestrutura de ensino com um amplo espaço verde, que proporciona práticas educacionais e projetos voltados 
para a aprendizagem dos discentes na educação ambiental. A IES localiza-se em uma área afastada do centro da cidade de Bragança/Pará.

A segunda parte da pesquisa foi desenvolvida na elaboração de questionários e na caracterização dos docentes dessa IES. O questionário foi composto de 11 perguntas no total relacionadas às práticas, metodologias de ensino e a perspectiva dos docentes com relação a educação ambiental, e aplicados em fevereiro de 2015.

\section{REFERENCIAL TEÓRICO}

Segundo Loureiro (2004) Educação Ambiental significa transformar, conscientizar, emancipar e exercer a cidadania em Educação e para o ambientalismo, enquanto movimento histórico de ruptura com a modernidade capitalista. Mostrando desta forma que o desenvolvimento de uma consciência ambientalmente correta em nossa sociedade deve se iniciar da educação.

A educação ambiental ganhou uma maior relevância nacional após instituição da Política Nacional de Educação Ambiental no ano de 1999, onde se estabeleceu no Brasil, posteriormente a um longo processo de discursões entre os educadores e ambientalistas, a obrigatoriedade da educação ambiental em todos os níveis de ensino formal e não-formal estabelecidos no país. (Brasil, 1999).

Em seu Art. $2^{\circ}$ a lei 9.795 expõem à importância da educação ambiental em relação ao processo educacional brasileiro da seguinte forma. "A educação ambiental é um componente essencial e permanente da educação nacional, devendo estar presente, de forma articulada, em todos os níveis e modalidades do processo educativo, em caráter formal e não-formal." (Brasil, 1999).

Todo esse aparato de informações legais quanto a obrigatoriedade do conhecimento educacional do meio ambiente nos leva a percepção de Chalita (2002) expondo a ideia de que a educação constitui-se na mais poderosa de todas as ferramentas de intervenção no mundo para a construção de novos conceitos e consequente mudança de hábitos. Essa mudança de conceito e hábitos por meio da educação quando relacionada à questão ambiental nós leva a acreditar na possibilidade futura de se ter uma sociedade ecologicamente sustentável. 
Segundo Carvalho (2006) a educação ambiental tem assumido nos últimos anos o grande desafio de garantir a construção de uma sociedade sustentável, em que se promovam na relação com o planeta e seus recursos, valores éticos como cooperação, solidariedade, generosidade, tolerância, dignidade e respeito à diversidade. Esse sentimento de uma sociedade sustentável e esses valores éticos com relação ao planeta poderá ter seus conceitos e atitudes iniciados e desenvolvidos dentro do círculo educacional uma vez que a conscientização social pode ser participativa por discentes e docentes no ambiente escolar e posteriormente disseminadas dentro de toda sociedade.

A relação da educação ambiental e a sustentabilidade é muito bem retratada pelo Tratado de Educação Ambiental para as sociedades sustentáveis e responsabilidade global que expõem o seguinte conceito:

\begin{abstract}
Consideramos que a educação ambiental para uma sustentabilidade equitativa é um processo de aprendizagem permanente, baseado no respeito a todas as formas de vida". Tal educação afirma valores e ações que contribuem para a transformação humana e social e para a preservação ecológica. Ela estimula a formação de sociedades socialmente justas e ecologicamente equilibradas, que conservam entre si relação de interdependência e diversidade. Isto requer responsabilidade individual e coletiva em nível local, nacional e planetário (JEA, 1992, p. 1).
\end{abstract}

Micaroni, et.al. (2010) revelam que a vivência na escola deve perpassar por um processo de significação despertando o desenvolvimento integral do indivíduo. A relação com o meio ambiente deve ser cultivada desde o início da pré-escola e dessa forma, a relação discente/docente se faz fundamental na execução de projetos com fins ambientais. $O$ ensino sobre o meio ambiente deve contribuir principalmente para o exercício da cidadania, estimulando a ação transformadora, além de aprofundar os conhecimentos sobre as questões ambientais e melhores tecnologias, estimulando a mudança de comportamentos e a construção de novos valores éticos menos antropocêntricos. A educação ambiental é fundamentalmente uma pedagogia de ação. Não basta ser mais consciente dos problemas ambientais sem se tornar também mais ativo, crítico e participativo. Em outras palavras, o comportamento dos cidadãos em relação ao seu meio ambiente, é indissociável do exercício da cidadania. 
A ação direta do professor na sala de aula é uma das formas de levar a Educação Ambiental à comunidade, pois um dos elementos fundamentais no processo de conscientização da sociedade sobre os problemas ambientais é o educador, porque este pode buscar desenvolver, em seus alunos, hábitos e atitudes sadias de conservação ambiental e respeito à natureza, transformando-os em cidadãos conscientes e comprometidos com o futuro do país. (SANTOS, 2002).

\section{METODOLOGIA}

A pesquisa desenvolvida possui caráter qualitativo e quantitativo, no sentindo que possa subsidiar o entendimento acerca dos desafios do ensino e percepção da educação ambiental no ensino superior. O trabalho foi dividido em três etapas: o levantamento bibliográfico dos temas afins, coleta de dados com aplicação de questionários aos docentes do ensino superior e a sistematização dos resultados com a geração de gráficos,

O levantamento bibliográfico foi feito em acervos, livros, teses, artigos e internet, onde os temas: educação ambiental, práticas de ensino e ensino superior, foram os focos do levantamento. Esse levantamento foi de suma importância, uma vez que possibilitou o diálogo entre diferentes autores, que tratam sobre o tema proposto, conceitos e discussões apresentados pelos teóricos que fundamentaram esta pesquisa no que tange ao conhecimento científico apresentado.

Carvalho (2006) contribui para o entendimento e importância da educação ambiental no processo formativo e educacional do sujeito social e ecológico, mensurando também o conceito de educação ambiental e suas interfaces com o processo educacional. Já Loureiro (2004) demostra a trajetória histórica e educacional da educação ambiental dentro do currículo escolar e propõe fundamentos para que esta área do conhecimento educacional. Dias (1992) corrobora com princípios e práticas metodológicas para a aplicação da educação ambiental nos diversos níveis formativos e/ou educacionais (ensino básico, médio e superior).

A partir da fundamentação teórica realizou-se a coleta de dados que se desenvolveu em três fases. Na primeira fase ocorreu a uma visita in locu ao instituto federal - campus Bragança, ou seja, apenas um reconhecimento da 
área de estudo considerando a observação empírica; levando em consideração a estrutura física e o quadro de docente da IES.

A segunda fase consistiu na elaboração dos questionários e na caracterização dos docentes do nível superior. O questionário apresenta 11 perguntas abertas e fechadas de cunho correspondentes às práticas, metodologia de ensino e formas de percepção ambiental dos docentes do ensino superior. Posteriormente fez-se a aplicação dos questionários aos professores. Sendo que esta etapa aconteceu no período de 23 a 27 de fevereiro de 2015, de acordo com a disponibilidade de tempo de cada professor.

O questionário foi aplicado a (sete) docentes do quadro de profissionais da IES de diferentes áreas iniciais e titularidades, cabe ressaltar que esse quantitativo de professores não representa o total de docentes vinculados ao quadro profissional do IFPA, porém representam significativamente a maioria dos profissionais atuantes nos cursos de formação superior da mesma instituição e que estavam presentes no dia da pesquisa.

$\mathrm{Na}$ terceira fase da pesquisa foi realizada a análise e discussão dos resultados. De posse dos materiais e dados coletados para a pesquisa, fez-se a sistematização dos resultados. Os dados dos questionários foram tabulados e posteriormente gerados os gráficos automaticamente por um programa computacional. Por fim para exemplificar a metodologia utilizada neste trabalho segue o perfil esquemático (figura 01) abaixo:

Figura 01: Perfil esquemático da metodologia utilizada

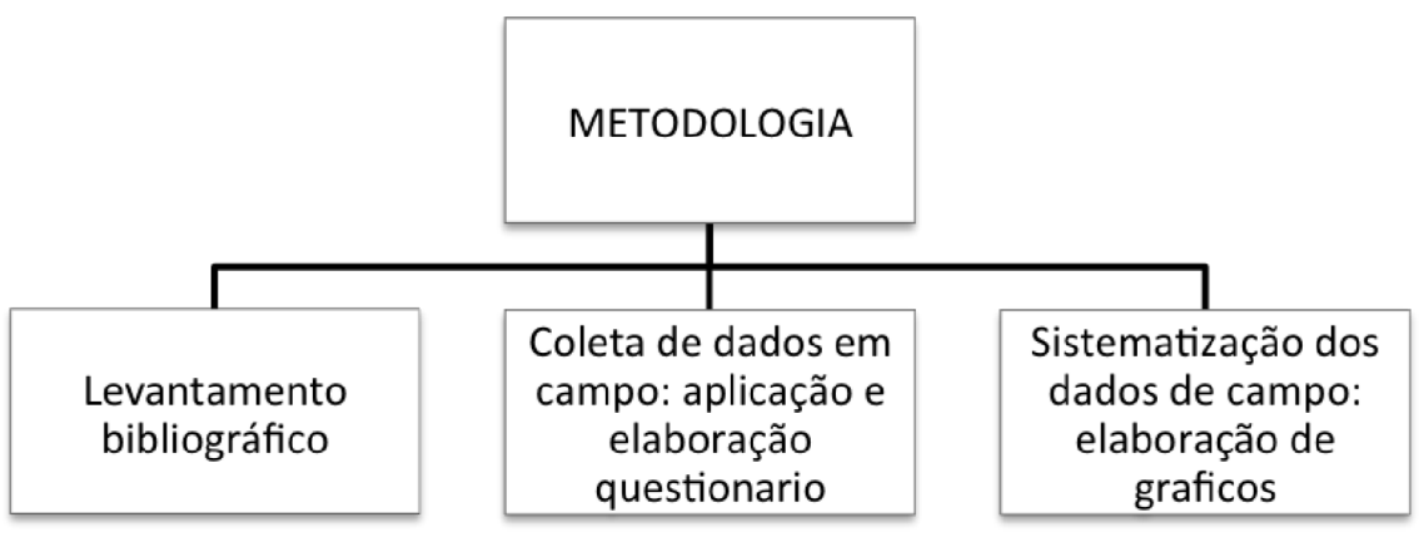

Fonte: autores. 


\section{ANÁLISE E INTEPRETAÇÃO DE DADOS}

$\mathrm{Na}$ primeira visita ao campus pode se identificar os cursos superiores disponibilizados pala instituição; Tecnologia em Agroecologia, Tecnologia em Gestão Ambiental e Física, os dois primeiros possuem uma forte relação com meio ambiente o que possibilita uma maior sensibilidade para a aplicação e compreensão dos docentes e discentes a respeito da educação ambiental, já o curso de Física possivelmente deve gerar um maior desafio para o docente com relação da aplicabilidade desse conhecimento em cada disciplina.

Decorrente da maioria dos cursos envolverem questões relacionadas ao meio ambiente grande parte do corpo docente da instituição possui um nível de formação dentro da área ambiental, o que gera a oportunidade de uma melhor atuação desses profissionais com a abordagem da educação ambiental em sala de aula e com seus alunos, uma vez que esse assunto foi visto pelo discente dentro de sua formação acadêmica, e poderão ser desenvolvidas em suas práticas em sala de aula.

No desenvolvimento dessa parte da pesquisa se buscou por meio de questionários aplicados aos professores do Instituto Federal do Pará - Campus Bragança, entender o ponto de vista de cada docente da instituição dentro da vertente da Educação Ambiental, a sua aplicabilidade de forma transversal no ensino superior e os desafios encontrados para a implantação ou disseminação dessas informações nas diversas linhas do conhecimento aplicado no Instituto.

No questionário buscou-se abordar as principais questões relacionadas ao desenvolvimento de atividades na instituição com abordagens que rodeiam a educação ambiental, procurou-se também entender o nível de percepção e conhecimento específico de cada docente com relação a esse assunto uma vez que se faz de grande importância ter um conhecimento concreto a respeito de qualquer assunto antes de aborda-lo de forma transversal como se é proposto pela lei de diretrizes e bases da educação.

Por meio do questionário puderam-se entender as dificuldades de cada docente em aplicar métodos e práticas da educação ambiental dentro das suas disciplinas, e se buscou entender se a própria instituição possibilita por meio de 
laboratórios e/ou com a própria grade curricular de cada curso a aplicação da educação ambiental nas diferentes formas de ensino.

Primeiramente buscou-se descobrir dentre os professores entrevistados quantos possuíam formação acadêmica na área ambiental, com o objetivo de compreender o grau de conhecimento que cada um possui a respeito da temática. O gráfico a baixo (Figura 01) expõem esses dados.

Figura 01 Gráfico relacionado à formação dos docentes na área ambiental.

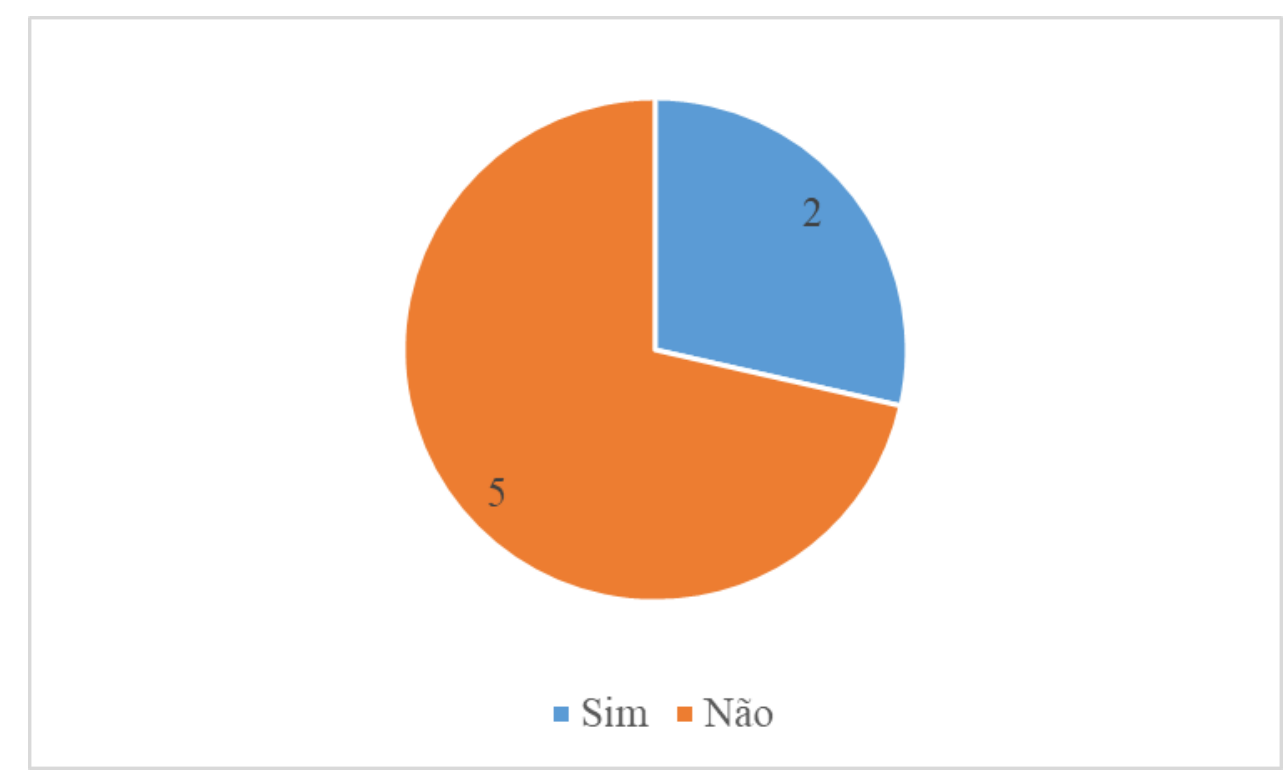

Fonte: Dados coletados em Campo 2015

Pode-se ver no gráfico que 5 dos professores entrevistados possuem formação na área ambiental o que possivelmente eleva o percentual de chances para o melhor desenvolvimento de atividades em relação à educação e conscientização ambiental com os alunos da instituição, pois uma vez que a maioria desses profissionais já possui conhecimento dentro dessa área a disseminação dessas informações se torna mais produtiva.

A grande quantidade de docentes formados na área ambiental está relacionada a possibilidade da instituição em disponibilizar cursos superiores dentro dessa mesma área, o que gera a exigência de possuir um quadro funcional de docentes com essa formação. Outras instituições de ensino acabam não tendo muitos profissionais com essa formação em seu quadro efetivo devido à demanda de cursos disponibilizados, o que leva a falta de um 
profissional com uma visão interdisciplinar do meio ambiente e que seria de grande valia para trabalhar com a educação ambiental em suas disciplinas.

Buscou-se entender o nível acadêmico de cada docente da instituição perguntando ao mesmo sua formação atual, especialista, mestre, doutor e pós doutor, para que obtivéssemos basicamente dados a respeito do grau de conhecimento dos profissionais da instituição, o que possibilitou com esses dados à geração no gráfico a baixo (Figura 02). 
Figura 02 Gráfico relacionado à titulação dos docentes entrevistados.

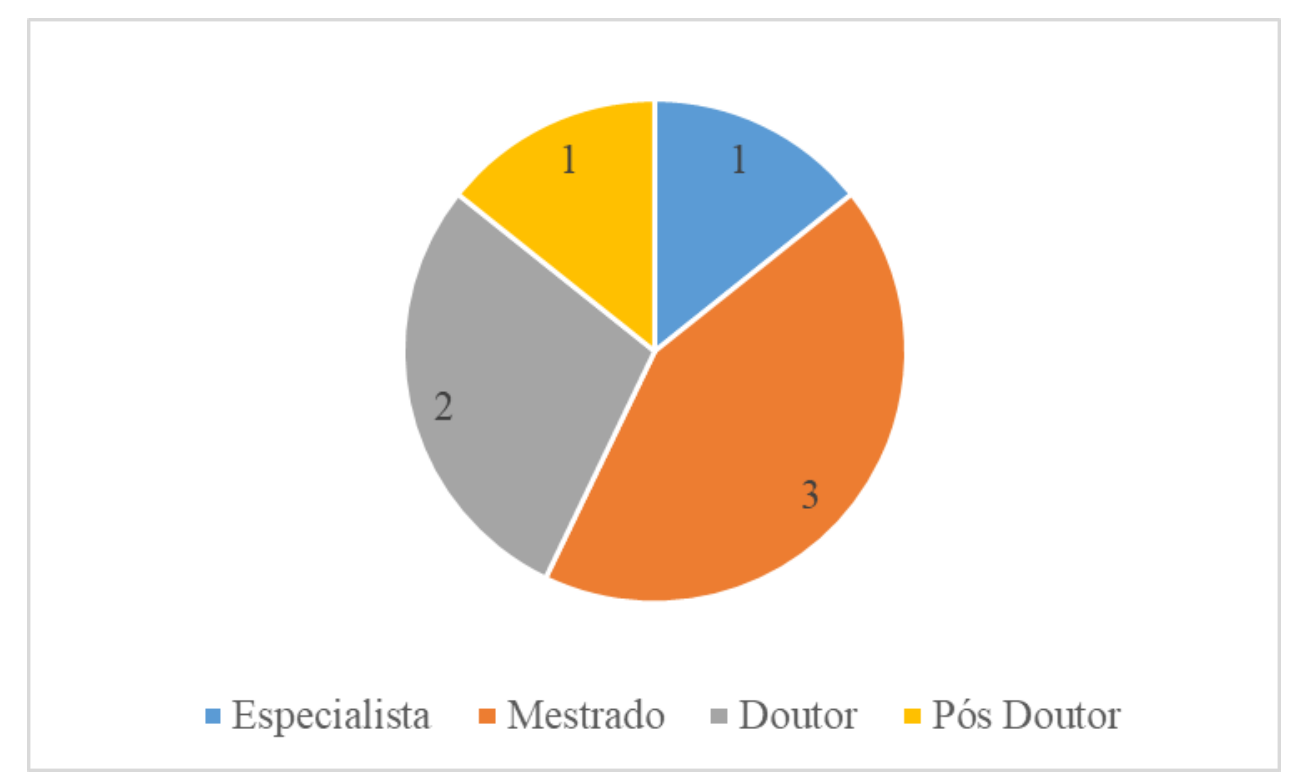

Fonte: Dados coletados em Campo 2015.

Dentro da pesquisa pode-se ver que 3 docentes possuem mestrado, 2 tem doutorado, 1 possui pós-doutorado e apenas 1 é especialista, o que mostra um nível elevado titulação do corpo docente do instituto e como a maior parte possui formação dentro da área ambiental melhora ainda mais a discussão e desenvolvimento de atividades relacionadas à questão ambiental o que também possibilita o melhor desenvolvimento da educação ambiental na instituição.

Também foi desenvolvido um gráfico relacionado ao tempo de atuação no ensino superior desempenhado por esses docentes, uma vez que o período de trabalho desse profissional dentro desse nível de ensino requer uma grande demanda de conhecimento e se torna de estrema importância à experiência em sala de aula. O gráfico abaixo expõem esses dados (Figura 03). 
Figura 03 Gráfico do tempo de atuação no ensino superior do corpo docente.

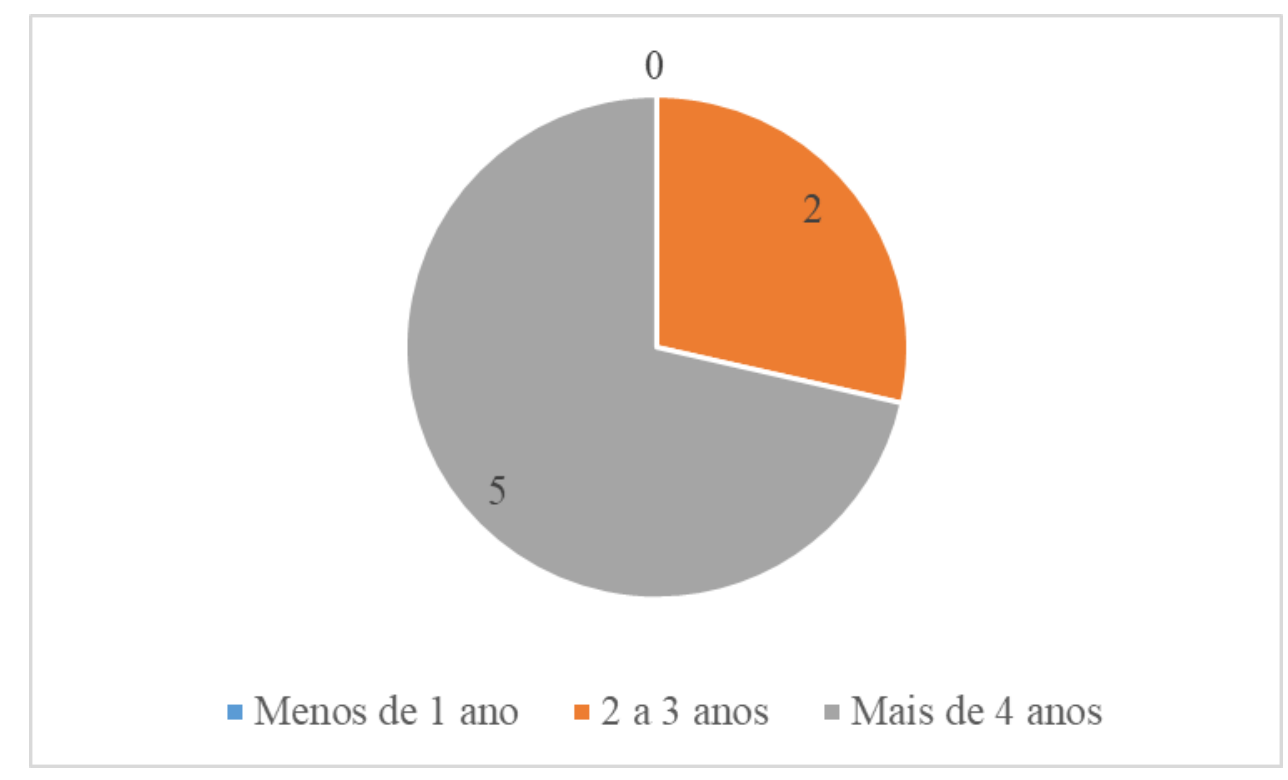

Fonte: Dados coletados em Campo 2015.

O tempo de docência e a experiência é um fator muito importante para cada profissional, no ensino superior não é diferente, dentre os professores entrevistados no instituto temos 5 dos profissionais atuando nos cargos de docente por mais de 4 anos o que é bastante interessante para instituição uma vez que a experiência desse profissional acaba sendo elevada, e apenas 2 trabalham como professores entre dois e três anos.

Foi levantado no questionário a questão da percepção de cada professor com relação à educação ambiental, para melhor nortear o desenvolvimento da pesquisa essa percepção se qualificou em três níveis; baixo, médio e alto no qual cada professor pode expor a sua avaliação própria de percepção ambiental (Figura 04). 
Figura 04 Gráfico do nível de percepção ambiental do docente.

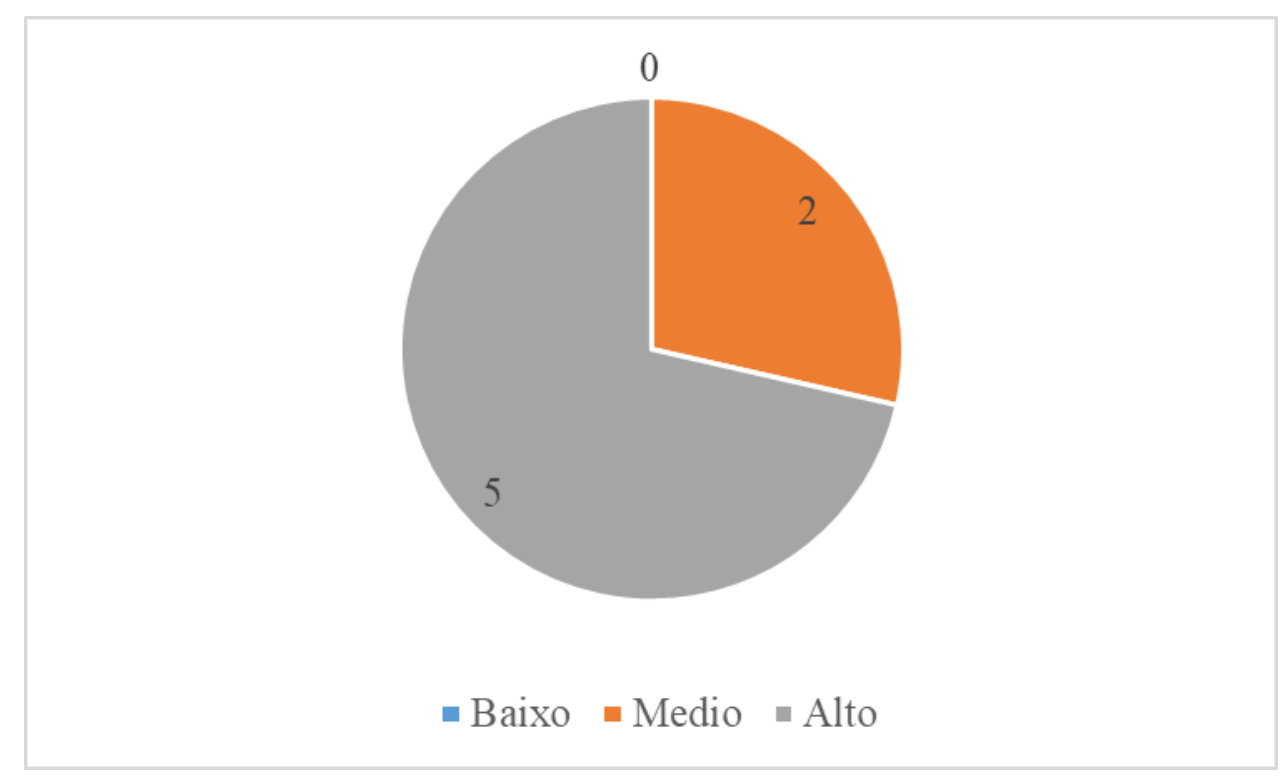

Fonte: Dados coletados em Campo 2015.

Pode se ver que em uma autoavaliação de cada docente sobre seu nível de percepção quanto à educação ambiental, 5 se consideraram com um nível de conhecimento ambiental alto o que nos remete a ideia de que a maior parte dos docentes da instituição se considera ter um bom desenvolvimento em sala com esse assunto.

Apenas 2 se consideraram com um nível médio de percepção a esse assunto e nenhum professor se delimitam com um nível baixo de percepção, o que é um bom fator para a própria instituição quando relacionada à educação ambiental por ter profissionais que entendem que a mesma deve ser desenvolvida no ensino de cada disciplina.

Outro questionamento feito aos professores está relacionado ao suporte que a instituição dá para o desenvolvimento da educação ambiental em sala de aula, se os professores são instruídos pela instituição a desenvolver esse assunto com os alunos em sala. O gráfico abaixo mostra resultado desses dados (Figura 05). 
Figura 05 Gráfico relacionado ao apoio dado ao docente pela instituição para abordagens da educação ambiental com os discentes.

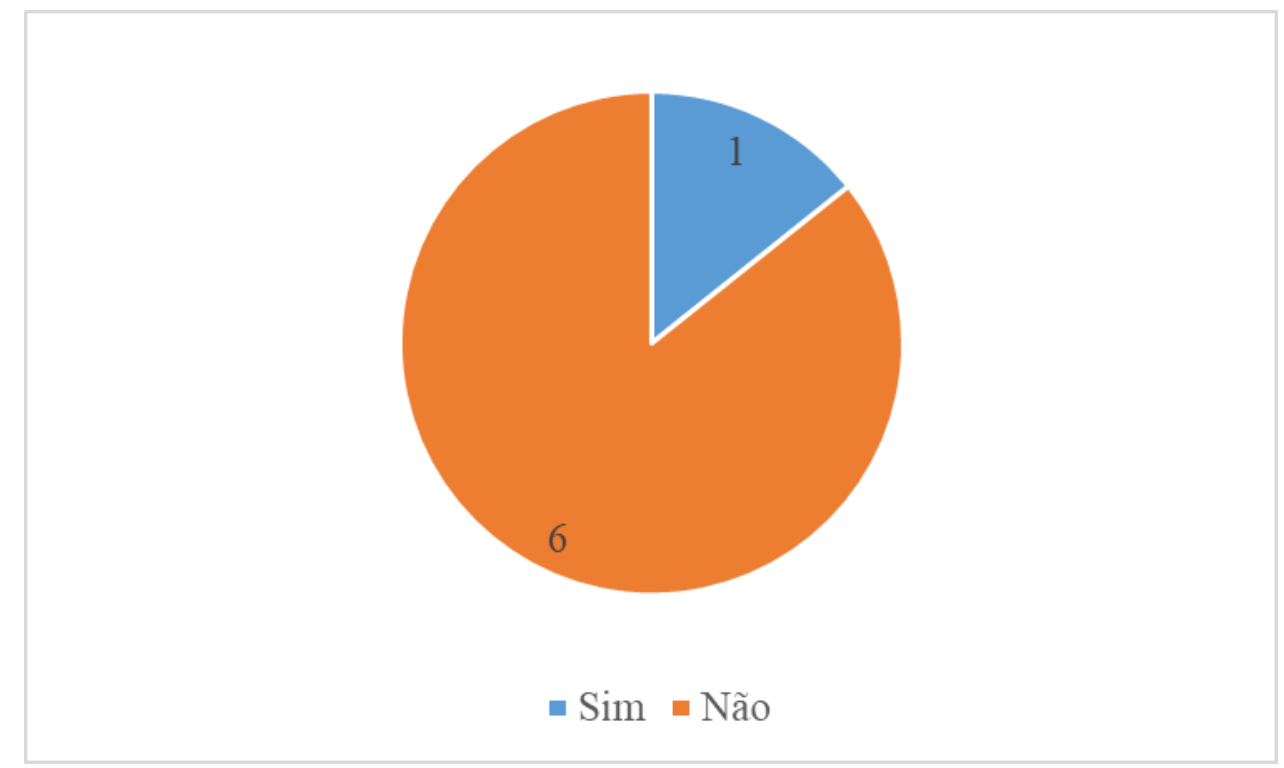

Fonte: Dados coletados em Campo 2015.

Com relação ao apoio oferecido pelo instituto federal para desenvolver abordagens relacionada à educação ambiental, 6 dos professores disseram que recebem apoio da IES, uma vez que existem os cursos na instituição com enfoque ambiental e são desenvolvidas nesses cursos aulas práticas e teóricas dentro dessa vertente, mas ausenta-se de um desempenho efetivo para práticas e ações metodológicas além das salas de aula.

Foi exposto por uma pequena parcela dos professores $14 \%$ que essa questão é pouco desenvolvida e abordada, que só recentemente dentro da jornada pedagógica que ocorreu na instituição que essa questão veio ser levantada aos professores. O que se torna preocupante é a forma que esse conhecimento está sendo repassado ou cobrado pela instituição para ser desenvolvido pelo docente.

Outra questão levantada foi à relação da grade curricular dos cursos superiores da instituição, se a mesma possibilitava aos professores desenvolver em suas aulas a educação ambiental de forma integrada as disciplinas dos cursos. Foi gerado um gráfico correspondente ao percentual de cada professor que participou da pesquisa, ver a (Figura 06). 
Figura 06 Gráfico relacionado à grade curricular dos cursos superiores e sua capacidade para desenvolvimento da educação ambiental pelos docentes.

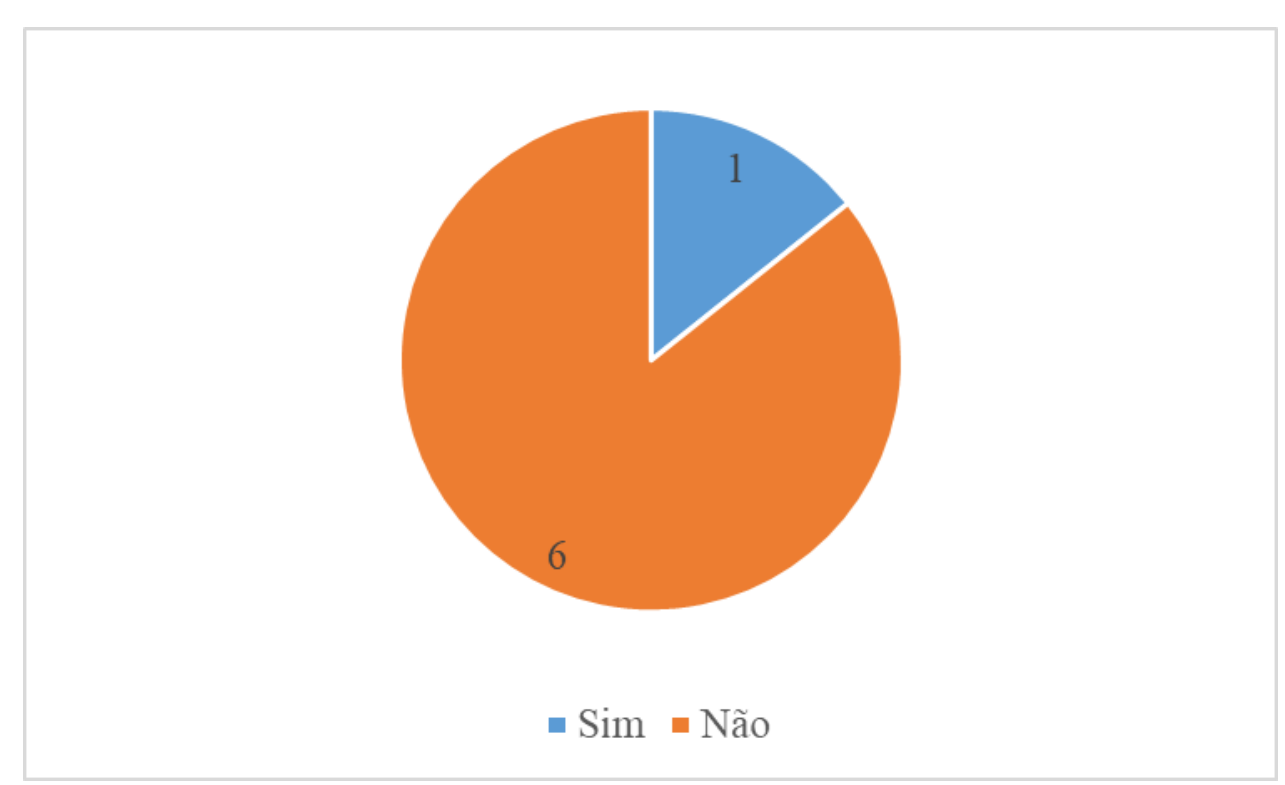

Fonte: Dados coletados em Campo 2015.

Com relação a grade curricular dos cursos da instituição 6 dos docentes disseram que é possível o desenvolvimento da temática da educação ambiental nos cursos superiores, pois possuem cursos voltados para área ambiental dando essa possibilidade e os conteúdos abordados são abrangentes. O curso de Física mostrou-se empenhadamente em enveredar pela aplicação da educação ambiental em seus métodos de ensino, dependendo do compromisso de cada professor em buscar trabalhar a melhor forma dessa inter-relação.

Os $14 \%$ dos docentes que responderam não para essa questão, expuseram que as ementas dos cursos determinam o que deve ser utilizado no plano de ensino e não possibilita o desenvolvimento de outras formas de ensino dentro das disciplinas, o que mostra uma visão isolada a respeito dessa abordagem uma vez que foi exposto pela maior parte dos docentes que a educação ambiental pode ser desenvolvida em qualquer curso da instituição.

Também buscou entender se os recursos oferecidos em laboratórios da instituição possibilitavam o desenvolvimento de práticas direcionadas à educação ambiental dos discentes, independente da área de atuação ou disciplina ministrada pelo professor. Assim, foi gerado um gráfico em cima desses dados. (Figura 07). 
Figura 07 Gráfico relacionado à disponibilidade dos laboratórios da instituição para aplicação de práticas envolvendo a educação ambiental.

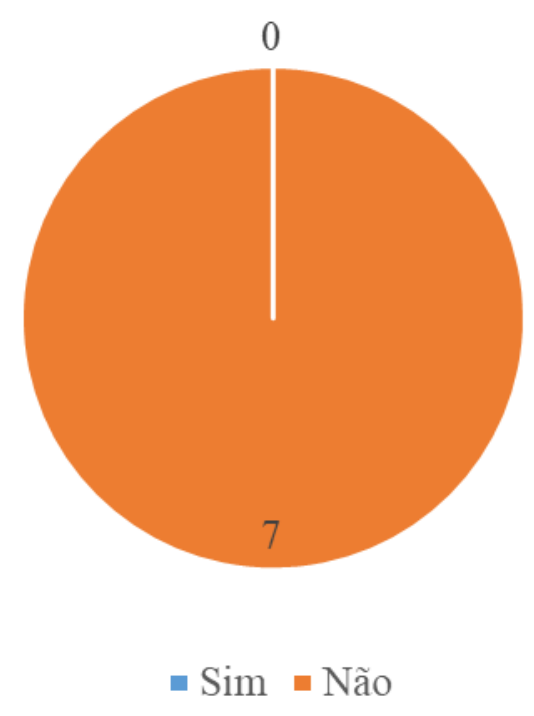

Fonte: Dados coletados em Campo 2015.

Um fato bem interessante levantado na pesquisa foi a respeito dos laboratórios do instituto e sua disponibilidade em desenvolver práticas relacionadas à educação ambiental, onde os 7 entrevistados responderão que não possui condição da aplicação de qualquer atividade voltada para essa questão. Muitos docentes alegaram que falta dos laboratórios dificultam 0 desenvolvimento de práticas da educação ambiental nos cursos do IFPA.

Os professores também mencionaram que alguns laboratórios até foram desativados como o de geografia por não possuírem demanda para seu uso, a falta de material, recursos e equipamento para aplicação de atividades. Outra abordagem feita pelos professores foi adequação desses espaços para um melhor uso podendo ser a solução para esse problema.

Outra questão que se procurou entender está relacionada ao desenvolvimento da educação ambiental como disciplina transversal, onde se buscou o entendimento desses docentes a respeito da mesma se tornar uma disciplina especifica em todos os níveis da educação, e os dados obtidos estão no gráfico abaixo (Figura 08). 
Figura 08 Gráfico relacionado à educação ambiental ser desenvolvida como uma disciplina especifica em todos os níveis de ensino.

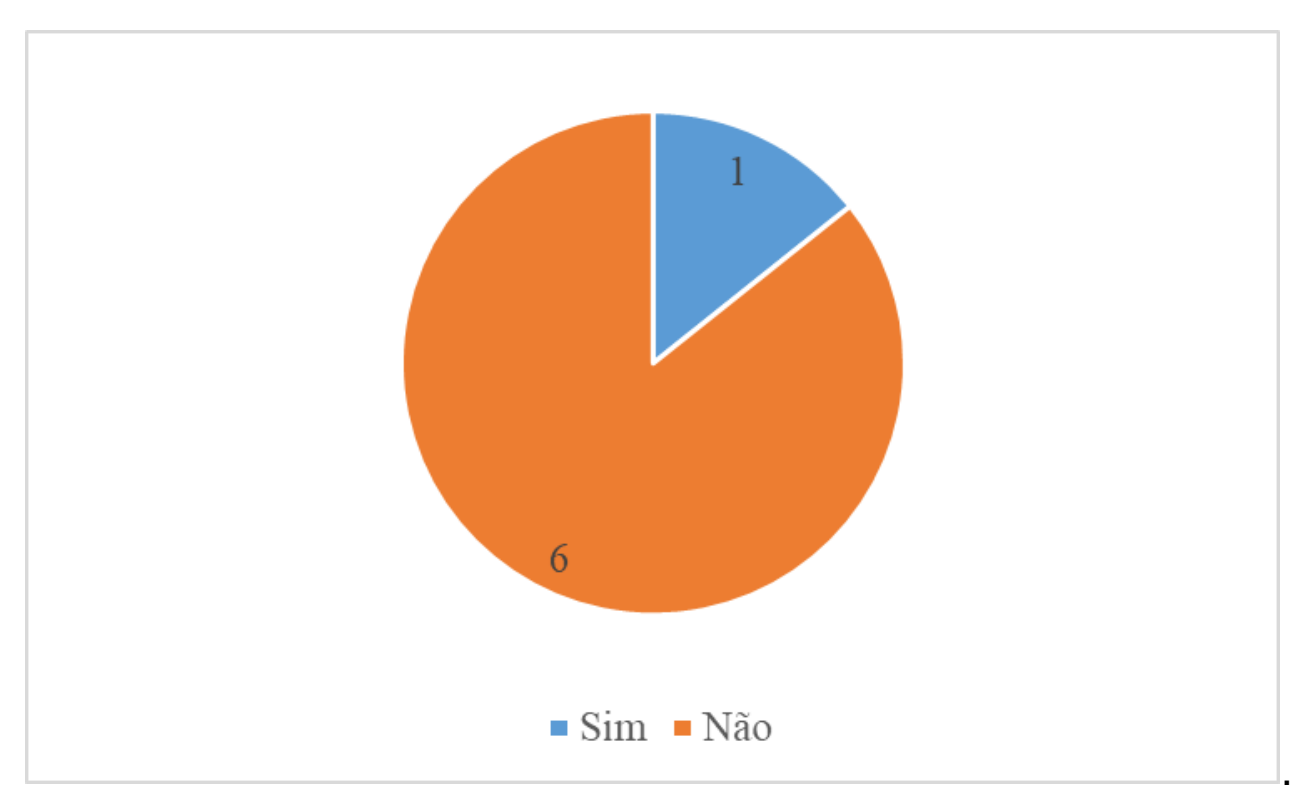

Fonte: Dados coletados em Campo 2015.

Quando perguntado aos docentes se a educação ambiental deveria ser uma disciplina especifica em todos os níveis de ensino, 6 disseram que sim ela deveria ser trabalhada desde 0 fundamental até 0 nível superior separadamente devido a sua grande importância para cada cidadão, e que tudo está relacionado ao meio ambiente então, o conhecimento a respeito deveria ser repassado desde cedo e com mais compromisso.

Outros docentes relataram que quando se trata de preservação do planeta a conscientização ambiental se torna de grande importância e que a educação ambiental deve ser aplicada se possível por meio de disciplina especifica dentro processo de ensino, pois todo assunto transversal como atualmente ele desenvolvido dentro de todas as disciplinas, acaba sendo tratado sem compromisso algum pelos docentes em qualquer categoria da educação.

Por meio de pergunta aberta, se buscou entender de cada professor qual seria o maior desafio no ensino superior para aplicação da educação ambiental, e essas respostas se relacionaram; a formação dos professores, a falta de laboratórios para o desenvolvimento de práticas dentro dessa temática, adequação curricular, metodologias relacionadas à educação ambiental que 
nem sempre podem ser usadas na instituição ou no ensino superior e a falta de investimentos em aulas práticas e atividades direcionadas.

Outro fato abordado com os docentes foi relacionado à definição de cada docente sobre educação ambiental, a qual foi relatada em diversas vertentes; como uma disciplina voltada para educação formal e não formal de pessoas no intuito orientar o comportamento humano e alcançar a sustentabilidade; como uma prática educativa e com o objetivo de tornar harmônica a convivência entre o homem e a natureza; como um conjunto de ações práticas e teóricas referentes as várias vertentes que o homem possui com o meio ambiente; e também como uma forma de levar o conhecimento sobre a necessidade de preservação do meio ambiente para outras pessoas.

Todas essas definições podem ser usadas como exemplo para o desenvolvimento da educação ambiental no ensino superior, e como os docentes possuem um conhecimento considerável do tema em questão, e o que se deve ser trabalhado especificamente são as dificuldades na aplicação desse conhecimento com relação à adequação curricular, metodologias, laboratórios e etc.

\section{CONSIDERAÇÕES FINAIS}

A mudança deve começar o quanto antes, haja vista de tratar-se de uma instituição de ensino superior que desenvolve o pensamento de seus alunos e da sociedade, seria de extrema importância que essas novas atitudes fossem construídas pelo corpo docente juntamente com a coordenação pedagógica, trazendo para dentro das salas novas perspectivas e direcionamentos dentro dessa vertente, o que potencializaria mudanças de comportamentos inicialmente nos alunos, que estariam envolvidos diretamente com esse processo.

Para estimular os alunos, uma boa técnica é estabelecer parceiras com os grupos ecológicos comunitários do lugar, convidando-os para se integrarem ao trabalho na escola. Logo a seguir procurando engajar-se nas ações da sociedade em defesa do meio ambiente e da qualidade de vida social o que potencializaria o envolvimento da sociedade em ações ambientais na região, 
progredindo para uma sociedade com uma correta compreensão a cerca da preservação do meio ambiente.

Com relação à necessidade da educação ambiental nos currículos do ensino superior da instituição, podemos ver que mesmo no curso que não possuem grande relação com a área ambiental se tem a possibilidade do desenvolvimento de forma transversal da temática, mas que os currículos necessitam de algumas adequações para o melhor desenvolvimento desse assunto nos cursos da instituição.

Os principais desafios relatados pelos docentes para o desenvolvimento dessa temática na instituição foram relacionados ao compromisso e formação dos próprios docentes que deve ser trabalhada de forma continua, a falta de investimentos em laboratórios, aula prática e atividades relacionadas à educação ambiental, e a adequação curricular devem ser vistas com atenção para que se tenha uma melhor possibilidade de desenvolver esse tema em qual curso da instituição.

No que tange a questão do conhecimento em relação ao conceito dos docentes da instituição sobre educação ambiental, podemos ver uma percepção bem ampla com relação ao assunto e que mesmo de forma diferente deve expor seus conceitos quanto ao tema, o qual evidenciaram um bom entendimento sobre a questão ambiental e a importância da aplicação teórica e prática da educação ambiental. 


\section{REFERÊNCIAS}

1a Jornada de Educação Ambiental - JEA: Tratado de Educação Ambiental para as sociedades sustentáveis e responsabilidade global, Rio de Janeiro, 1992.

BARRETO, Aldo de Albuquerque, A Questão da informação, Revista São Paulo em Perspectiva, Fundação Seade, v8, n4, 1994.

BRASIL. Ministério do Meio Ambiente. Lei n. 9.795/1999. Dispõe sobre a educação ambiental, institui a Política Nacional de Educação Ambiental e dá outras providências. Disponível em:<http://www.planalto.gov.br/ccivil_03/leis//9795.htm>. Acesso em: 11 maio. 2016.

CARVALHO, I. C. de M. Educação Ambiental: Formação do Sujeito Ecológico. 2 2a edição. São Paulo, Cortez, 2006.

CHALITA, G. Educação: a solução está no afeto. São Paulo: Gente, 2002. DIAS, G. F. Educação Ambiental: Princípios e Práticas. 3aㅗ ed. São Paulo; Gaia, 1992.

JUNIOR, A. P. E PELICIONI, M. Educação Ambiental e Sustentabilidade. 1ª ed. Barueri-SP. Manolie, 2005.

LOUREIRO, C.F.B., Trajetória e fundamentos da Educação Ambiental. São Paulo: Cortez, 2004.

MEIRELLES, M de S.; SANTOS, M. T. Educação Ambiental uma Construção Participativa. $2^{a}$ ed. São Paulo, 2005.

MICARONI, N. I. R.; CRENITTE, P. A. P.; CIASCA, S.M. A Prática Docente Frente À Desatenção dos Alunos No Ensino Fundamental. Revista CEFAC, p.756-765, 2010. Disponível em: <http://www.scielo.br/pdf/rcefac/v12n5/13708.pdf>. Acesso em: 02 set. 2016.

MININNI, N.M. "Elementos para a introdução da dimensão ambiental na educação escolar - 1ำ grau". Amazônia: uma proposta interdisciplinar de educação ambiental. Brasília, IBAMA. 1994.

SANTOS, R.C., et al. A Caminho da Sustentabilidade. In: MINAS GERAIS. Secretaria de Estado da Educação. Santos, C. P. (Coord.). Educação Ambiental: ação e conscientização para um mundo melhor. - Belo Horizonte: SEE/MG, 2002.144p. (Lições de Minas, v. 17). 
AMBIENTE \& EDUCAÇÃO

ISSN - 1413-8638

E-ISSN - 2238-5533

v. 24, n.1, p.32-53, 2019 